\title{
Investigation of the structural and optical properties of copper-titanium oxide thin films produced by changing the amount of copper
}

\author{
Seyda Horzum ${ }^{\mathrm{a}, *}$, Sibel Gürakar ${ }^{\mathrm{b}}$, Tülay Serin ${ }^{\mathrm{b}}$ \\ ${ }^{a}$ Department of Physics, Izmir Institute of Technology, 35430 Izmir, Turkey \\ ${ }^{\mathrm{b}}$ Department of Physics Engineering, Ankara University, 06100, Tandoğan, Ankara, Turkey
}

\section{A R T I C L E I N F O}

\section{Keywords:}

Thin films

Sol-gel deposition

Copper-titanium oxide

Band gap

Refractive index

Raman spectroscopy

\begin{abstract}
A B S T R A C T
We examine how the structural, morphological and optical properties of $\mathrm{TiO}_{2}$ thin films are changed with heavily copper $(\mathrm{Cu})$ content. Variations in characteristic properties of the films with $0,12.5,25 \mathrm{and} 50 \mathrm{wt} \% \mathrm{Cu}$ contents, grown by sol-gel dip coating method, are observed by using X-ray diffraction (XRD), Raman scattering, atomic force microscopy, energy dispersive X-ray analysis and optical spectroscopy measurements. The XRD and Raman spectra indicate that pure $\mathrm{TiO}_{2}$ film forms in the anatase structure. At high $\mathrm{Cu}$ concentrations, XRD results also reveal the substitution of $\mathrm{Ti}$ with $\mathrm{Cu}$ and formation of extra compound Copper-Titanium oxide. Raman measurements also show that $\mathrm{Cu}$ is incorporated homogeneously into $\mathrm{TiO}_{2}$ matrix up to $12.5 \mathrm{wt} \%$ concentration and this uniformity is distorted at higher $\mathrm{Cu}$ contents. In addition, optical spectroscopy measurements show that the optical band gap energy decreases from $3.26 \mathrm{eV}$ to $2.05 \mathrm{eV}$ with increasing $\mathrm{Cu}$ concentration. Furthermore, it is observed that the refractive index values obtained by means of transmittance spectra at $550 \mathrm{~nm}$ wavelength; increases from 2.47 to 3.39 when the $\mathrm{Cu}$ concentration increases from 0 to $50 \mathrm{wt}$ $\%$.
\end{abstract}

\section{Introduction}

In recent years, titanium oxide $\left(\mathrm{TiO}_{2}\right)$ has been one of the widely examined metal oxides due to its notable properties such as good durability, high dielectric constant and high refractive index. $\mathrm{TiO}_{2}$ films are used for their potential applications in optical components including dye sensitized solar cells, optical filters, photocatalysts, humidity and gas sensors [1-5]. The optoelectronic applications of $\mathrm{TiO}_{2}$ are limited in the visible region of the spectrum due to the wide band gap of $\mathrm{TiO}_{2}$ $(3.3 \mathrm{eV})$. Also, the high recombination rate of photogenerated electronhole pairs are one of the factors affecting the optical and electrical properties of $\mathrm{TiO}_{2}$.

In order to enhance the characteristic properties of wide band gap semiconductor, the doping is an efficient method. Therefore, many studies have focused on doping with the transition metals $(\mathrm{Mn}, \mathrm{Ni}, \mathrm{Cu}$, $\mathrm{Fe}$ ) to improve and control the characteristic properties of $\mathrm{TiO}_{2}$ films [6-8]. Among the transition metal atoms, $\mathrm{Cu}$ is the most remarkable one since the radius of $\mathrm{Cu}^{2+}(0.72 \AA)$ is close to the radius of $\mathrm{Ti}^{4+}$ $(0.68 \AA)$, C can easily be added to the $\mathrm{TiO}_{2}$ lattice [9]. Zhang et al. reported that the substitution of $\mathrm{Ti}^{4+}$ by $\mathrm{Cu}^{2+} / \mathrm{Cu}^{1+}$ in the $\mathrm{TiO}_{2}$ lattice causes to the creation of oxygen vacancies and additional impurity band, which leads to reduce band gap and lower recombination rate of photo electron-hole pairs [10]. Thus, photocatalytic performance and the ability of visible light absorption of $\mathrm{TiO}_{2}$ have been improved. Furthermore, Bensouici et al. investigated the effect of $\mathrm{Cu}$ doping on optical and photocatalysis properties of $\mathrm{TiO}_{2}[1]$. They showed that the optical band gap decreases while photocatalytic activity remains unchanged. Maeda et al. examined the photocatalytic activity of $\mathrm{Cu}, \mathrm{Fe}$ and $\mathrm{Al}$ doped $\mathrm{TiO}_{2}$ films grown by sol-gel process [11]. They observed that the $\mathrm{Cu}$ addition causes an effective increase in visible-light photocatalytic activity; unlike Fe- and Al-doped films. Moreover, Wang et al. demonstrated that $\mathrm{Cu}$ incorporated $\mathrm{TiO}_{2}$ film deposited by $\mathrm{RF}$ magnetron sputtering has partial rutile phase [12]. In addition, the structural, electrical properties and surface morphology of $20 \% \mathrm{Cu}$ doped $\mathrm{TiO}_{2}$ films grown by sol-gel process were investigated by Khan et al. [13]. They showed that new titanium copper oxide compounds formed when these films are exposed to laser beam. So far, in the studies that have been done to investigate the effect of $\mathrm{Cu}$ on $\mathrm{TiO}_{2}$ film properties, the highest amount of $\mathrm{Cu}$ in the films is $27.25 \%$ [14]. In this study, the effect of $\mathrm{Cu}$ incorporation at a high concentration (up to $50 \mathrm{wt} \%$ ) on the characteristic properties of $\mathrm{TiO}_{2}$ films is investigated. Pure $\mathrm{TiO}_{2}$ and Copper-Titanium oxide films at 12.5, 25 and $50 \mathrm{wt} \% \mathrm{Cu}$ content are deposited on glass substrates by means of the solution obtained by adding copper (II) acetate to the titanium tetraisopropoxide

\footnotetext{
* Corresponding author.

E-mail addresses: seydahorzum@iyte.edu.tr (S. Horzum), sgurakar@eng.ankara.edu.tr (S. Gürakar), serin@eng.ankara.edu.tr (T. Serin).
} 
solution. The sol-gel method is used in the deposition of the films, due to the homogeneous distribution of the added atoms in the coating solution. Moreover, the relationships between the optical, structural and morphological properties of the films are studied.

\section{Experimental}

Pure $\mathrm{TiO}_{2}$ and Copper-Titanium oxide thin films are deposited on clean glass substrates by sol-gel dip coating method using titanium tetraisopropoxide and copper (II) acetate as starting precursors. The amount of $\mathrm{Cu}$ in the solution is adjusted to be $0,12.5 \mathrm{wt} \%, 25 \mathrm{wt} \%$ and $50 \mathrm{wt} \%$. As a first step, the initial solution is obtained by dissolving copper (II) acetate $\left[\mathrm{Cu}\left(\mathrm{CH}_{3} \mathrm{COO}\right)_{2} \cdot \mathrm{H}_{2} \mathrm{O}\right]$ in $50 \mathrm{ml}$ ethanol $\left[\mathrm{C}_{2} \mathrm{H}_{6} \mathrm{O}\right.$, Merck]. During the solution is mixed on the magnetic stirrer, 3 drops of lactic acid is incorporated into it. Afterwards, $1.2 \mathrm{ml}$ titanium tetraisopropoxide [ $\mathrm{Ti}\left(\mathrm{OC}_{3} \mathrm{H}_{7}\right)_{4}$, Merck] is incorporated into the solution. In the final step, $1 \mathrm{ml}$ trietilamine $\left[\left(\mathrm{C}_{2} \mathrm{H}_{5}\right)_{3} \mathrm{~N}\right.$, Merck] is incorporated into the solution and the final solution is mixed for $2 \mathrm{~h}$ on the magnetic stirrer. After the preparation process, homogenous coating solution in blue-color is kept at room temperature in air for $24 \mathrm{~h}$. The sol-gel dipping process is performed using a micro controller motorized system at a fixed speed of $0.4 \mathrm{~mm} / \mathrm{s}$ for the deposition of films. After each dipping, films are put into the furnace at $300{ }^{\circ} \mathrm{C}$ for $5 \mathrm{~min}$ for the drying process. After ten dipping, the films are annealed at $500{ }^{\circ} \mathrm{C}$ temperature for $1 \mathrm{~h}$ in air. In order to investigate the microstructure of the deposited films, X-ray diffraction (XRD) measurements are performed by Rigaku Miniflex 600 Table Top Powder X-ray diffractometer using $\mathrm{CuK}_{\alpha}$ radiation source with a wavelength of $0.154 \mathrm{~nm}$ in the $2 \theta$ scanning range of $10-70^{\circ}$. Elemental composition of the films is investigated by using Zeiss scanning electron microscope equipped with energy dispersive Xray (EDX) analysis. Raman measurements are implemented by means of Horiba XploRA Raman spectrometer. In order to collect Raman-scattered light, an Olympus Bx41 transmission and reflection illumination microscope (Olympus, France) is employed by a $100 \times$ objective magnification $(\mathrm{NA}=0.90)$. Raman signals are recorded using the green laser excitation of $532 \mathrm{~nm}$ with grating 1200 grooves $/ \mathrm{mm}$ in a spectral range of $50-800 \mathrm{~cm}^{-1}$. The optical transmittance measurements in the UV-Vis-NIR range are performed by a Shimadzu 3600 spectrophotometer in the wavelength range of $300-1800 \mathrm{~nm}$. Atomic force microscopy (AFM) measurements are obtained by means of a SPM Solver-PRO (NT-MDT) in semi-contact mode. To observe the effects of $\mathrm{Cu}$ incorporation on the morphological properties of the films, the root mean square (RMS) values of surface roughness and the average grain size are also determined.

\section{Results and discussion}

In order to determine the influence of $\mathrm{Cu}$ content on the structural properties of Copper-Titanium oxide films, the crystal structure and orientation of the films are investigated by using XRD patterns (Fig. 1). The XRD measurements show that all films have diffraction peaks at $2 \theta=25.28^{\circ}, 2 \theta=37.84^{\circ}$ and $2 \theta=48.03^{\circ}$ which corresponds to the (101), (004) and (200) planes of $\mathrm{TiO}_{2}$ in the anatase structure, respectively [15]. It is also seen that for the preferred orientation along (101) plane. Wang et al. have pointed out that the addition of high concentration $\mathrm{Cu}$ to $\mathrm{TiO}_{2}$ causes to phase transformation from anatase to rutile at low temperature [14]. However, in our measurements, the XRD peaks of rutile $\mathrm{TiO}_{2}$ are absent since we use the different starting precursors and deposition method. The crystallite size of (101) plane is calculated by means of Debye Scherrer's formula and given in Table 1 . Furthermore, the diffraction peak of $\mathrm{CuO}$ and $\mathrm{Cu}_{2} \mathrm{O}$ species which is attributed to the interstitial of $\mathrm{Cu}$ ions is not observed [14].

Fig. 2 (a) demonstrates Raman spectra of Copper-Titanium Oxide films. The prominent Raman peaks observed for all samples at 143, 197, 397,517 and $639 \mathrm{~cm}^{-1}$ are related to typical anatase phase of $\mathrm{TiO}_{2}$. These peaks correspond to following Raman vibration modes: $E_{\mathrm{g}}$ modes

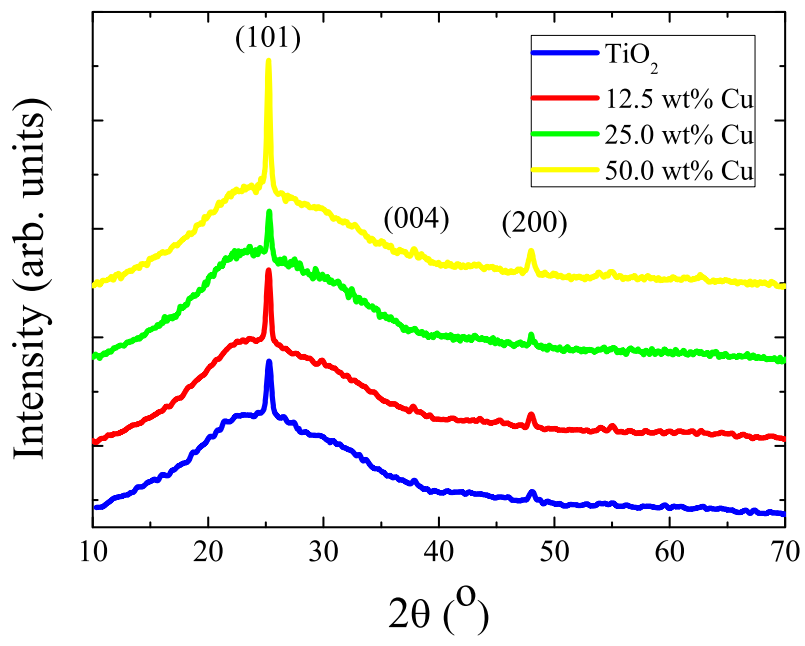

Fig. 1. XRD patterns of pure and Copper-Titanium oxide thin films.

at 143,197 and $639 \mathrm{~cm}^{-1}, B_{1 \mathrm{~g}}$ mode at $397 \mathrm{~cm}^{-1}$ and overlapped $A_{1 \mathrm{~g}}$ and $B_{1 \mathrm{~g}}$ modes at $517 \mathrm{~cm}^{-1}$. Fig. 2 (b) exhibits zoomed view of the strong $E_{\mathrm{g}}$ phonon mode which is existed at $143 \mathrm{~cm}^{-1}$. Such modes occur due to symmetric stretching vibrations of oxygen atoms in O-Ti-O bond [16-18]. The high frequency modes are also presented in Fig. 2 (c). The $B_{1 \mathrm{~g}}$ and $A_{1 \mathrm{~g}}$ modes exist with symmetric and antisymmetric bending vibration of O-Ti-O, respectively [19]. According to Raman spectra, all of the peaks shift and broaden with $\mathrm{Cu}$ incorporation. The $E_{\mathrm{g}}$ mode observed at $142.6 \mathrm{~cm}^{-1}$ in pure $\mathrm{TiO}_{2}$ shifts towards $149.0 \mathrm{~cm}^{-1}$ in $50 \mathrm{wt} \% \mathrm{Cu}$-incorporated films (Table 2). The frequency of $E_{\mathrm{g}}$ mode slightly shifts $\left(\Delta=1.6 \mathrm{~cm}^{-1}\right)$ for $12.5 \mathrm{wt} \%$ Cu-incorporated films while the shifting of frequency increases $\left(\Delta=6.4 \mathrm{~cm}^{-1}\right)$ for $50 \mathrm{wt} \% \mathrm{Cu}$-incorporated films. The incorporation of $\mathrm{Cu}$ distorts the lattice structure of $\mathrm{TiO}_{2}$ since the ionic radius of $\mathrm{Cu}^{+2}(0.72 \AA)$ is slightly larger than that of $\mathrm{Ti}^{+4}(0.68 \AA)$. Furthermore, because of the charge difference between $\mathrm{Cu}^{+2}$ and $\mathrm{Ti}^{+4}$, the addition of $\mathrm{Cu}^{+2}$ into the $\mathrm{TiO}_{2}$ matrix creates the oxygen vacancies to protect the charge neutrality in the lattice $[20,21]$ and the higher concentration of $\mathrm{Cu}^{+2}$ compose more oxygen vacancies in the $\mathrm{TiO}_{2}$ lattice. Since these oxygen vacancies are formed, the lattice distorts and the all Raman peaks shift and broaden, with increasing $\mathrm{Cu}$ content. However, the extra peak is observed at $297 \mathrm{~cm}^{-1}$ for $25 \mathrm{wt} \%$ and $50 \mathrm{wt} \%$ Cu-incorporated films while it is invisible for $12.5 \mathrm{wt} \% \mathrm{Cu}$ concentration. This extra peak existed with high $\mathrm{Cu}$ concentration is related to $A_{\mathrm{g}}$ mode of $\mathrm{CuO}$ [22]. $\mathrm{Cu}$ is incorporated homogeneously into the $\mathrm{TiO}_{2}$ matrix until $12.5 \mathrm{wt} \%$ concentration and higher $\mathrm{Cu}$ content breaks down this uniformity.

In order to reveal the elemental composition of Copper-Titanium Oxide films, EDX analysis is also carried out (Fig. 3). The EDX spectra is shown in Fig. 3 and proves the successful incorporation of $\mathrm{Cu}$ into the films. The values of weight percentage are presented in the inset table of Fig. 3. The film with $50 \mathrm{wt} \% \mathrm{Cu}$ is found as $45 \mathrm{wt} \%$ by means of EDX measurement. Only this value is smaller than the percentage of $\mathrm{Cu}$ placed in the solution.

The 2D AFM images of Copper-Titanium Oxide films are shown in Fig. 4. AFM images reveal the existence of nanograins. These results also show that the surface morphology changes with $\mathrm{Cu}$ incorporation and transforms into larger nanoparticle as a result of aggregation, as can be seen from Fig. 4 (c and d). The values of surface roughness and grain size determined by Gwyddion software for all films are given in Table 1. It is observed that surface roughness and grain size of the films increase with the increasing of $\mathrm{Cu}$ content. The grain size values of $\mathrm{Cu}$ incorporated films obtained from the AFM images are bigger than the crystallite size found from XRD, because grain composes of a few crystallites. However, it is seen that both of the grain size and crystallite size increase with the addition of $\mathrm{Cu}$. 
Table 1

XRD, AFM and UV-Vis spectra results of pure and Copper-Titanium oxide thin films.

\begin{tabular}{|c|c|c|c|c|c|c|c|c|}
\hline \multirow[t]{2}{*}{ Films } & \multicolumn{3}{|c|}{ XRD results } & \multicolumn{2}{|c|}{ AFM results } & \multicolumn{3}{|c|}{ UV-Vis spectra results } \\
\hline & $2 \theta\left({ }^{\circ}\right)$ & $\mathrm{d}(\AA ̊)$ & Crystallite size (nm) & $\begin{array}{l}\text { RMS } \\
(\mathrm{nm})\end{array}$ & Grain size(nm) & $\begin{array}{l}\text { Thickness } \\
\text { (nm) }\end{array}$ & $\begin{array}{l}E_{g} \\
(e V)\end{array}$ & $\begin{array}{l}n \\
(550 \mathrm{~nm})\end{array}$ \\
\hline $\mathrm{TiO}_{2}$ & 25.28 & 3.518 & 19.11 & 0.55 & 31.78 & 497 & 3.26 & 2.47 \\
\hline $12.5 \mathrm{wt} \% \mathrm{Cu}$ & 25.23 & 3.525 & 21.27 & 2.09 & 38.38 & 378 & 3.10 & 2.85 \\
\hline $25.0 \mathrm{wt} \% \mathrm{Cu}$ & 25.29 & 3.521 & 26.87 & 2.33 & 42.89 & 274 & 2.75 & 3.19 \\
\hline $50.0 \mathrm{wt} \% \mathrm{Cu}$ & 25.23 & 3.525 & 27.49 & 2.46 & 48.32 & 290 & 2.05 & 3.34 \\
\hline
\end{tabular}

The obtained transmittance spectra to explore optical properties of Copper-Titanium oxide thin films are shown in Fig. 5. It is seen that for pure $\mathrm{TiO}_{2}$ film as being colorless and transparent, the absorption starts at $390 \mathrm{~nm}$ in the UV-region. As the $\mathrm{Cu}$ atom is incorporated into the films, the color becomes darker, transmittance decreases and the absorption edge shifts to visible region. The absorption edge of CopperTitanium Oxide shifts to the visible region due to presence of $\mathrm{Cu}^{+2}$ subband state in the middle of band gap for indirect transition of the excited electrons from valence band to conduction band [14,23]. The interference fringes observed in the transmission spectra indicate that the film thickness has uniform distribution. The appearance of these fringes is due to the difference between reactive index of the film and glass substrate. Therefore, Swanepoel's envelope method is applied to derive the refractive index and thickness of the films [24]. Refractive index ( $n$ ), thickness (d) and absorption coefficient ( $\alpha$ ) of the deposited films are calculated by the following equations:

$\left.n=\left[N+\left(N^{2}-s^{2}\right)^{1 / 2}\right)\right]^{1 / 2}$

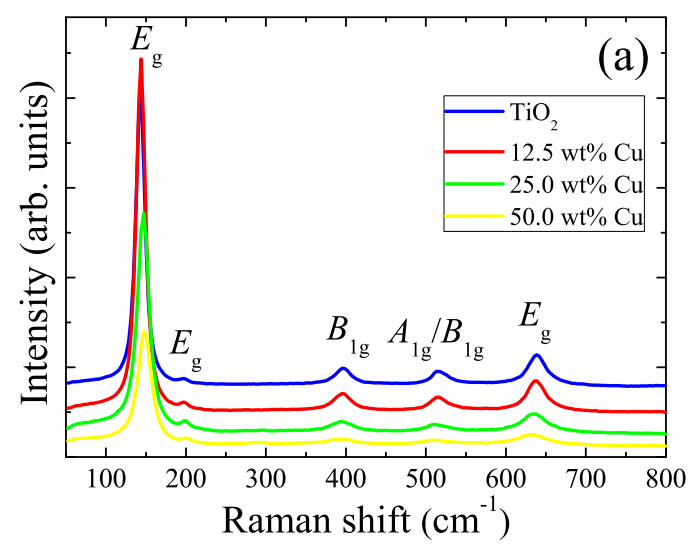

Table 2

The frequency values of phonon modes of pure and Copper-Titanium oxide thin films.

\begin{tabular}{llllll}
\hline Films & $E_{\mathrm{g}}\left(\mathrm{cm}^{-1}\right)$ & $E_{\mathrm{g}}\left(\mathrm{cm}^{-1}\right)$ & $B_{1 \mathrm{~g}}\left(\mathrm{~cm}^{-1}\right)$ & $\begin{array}{l}A_{1 \mathrm{~g}} / B_{1 \mathrm{~g}} \\
\left(\mathrm{~cm}^{-1}\right)\end{array}$ & $E_{\mathrm{g}}\left(\mathrm{cm}^{-1}\right)$ \\
\hline $\mathbf{T i O}_{\mathbf{2}}$ & 142.6 & 197.0 & 396.9 & 516.8 & 638.5 \\
$\mathbf{1 2 . 5} \mathbf{~ w t} \% \mathbf{C u}$ & 144.2 & 197.5 & 396.4 & 515.3 & 637.0 \\
$\mathbf{2 5 . 0} \mathbf{~ w t} \% \mathbf{C u}$ & 147.2 & 198.9 & 395.0 & 511.6 & 635.6 \\
$\mathbf{5 0 . 0} \mathbf{~ w t} \% \mathbf{C u}$ & 149.0 & 202.0 & 394.5 & 509.3 & 632.6 \\
\hline
\end{tabular}

$N=2 s \frac{T_{M}-T_{m}}{T_{M} T_{m}}+\frac{s^{2}+1}{2}$

$d=\frac{\lambda_{1} \lambda_{2}}{2\left(\lambda_{1} n_{2}-\lambda_{2} n_{1}\right)}$

$\alpha=\frac{1}{d} \ln \left(\frac{1}{T(\lambda)}\right)$

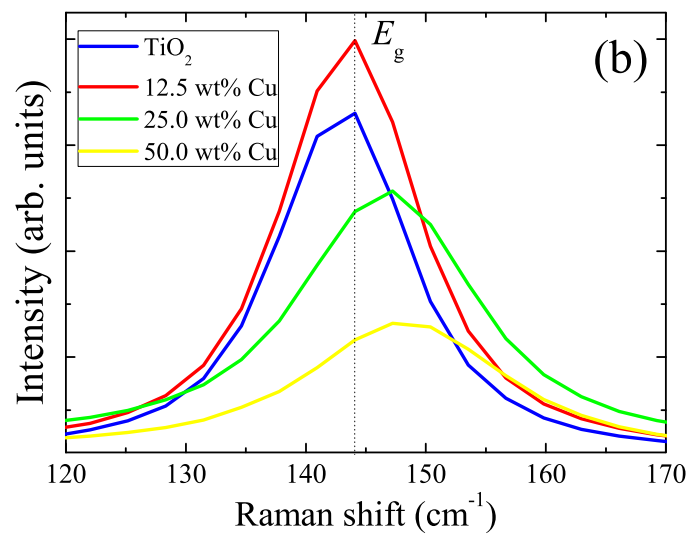

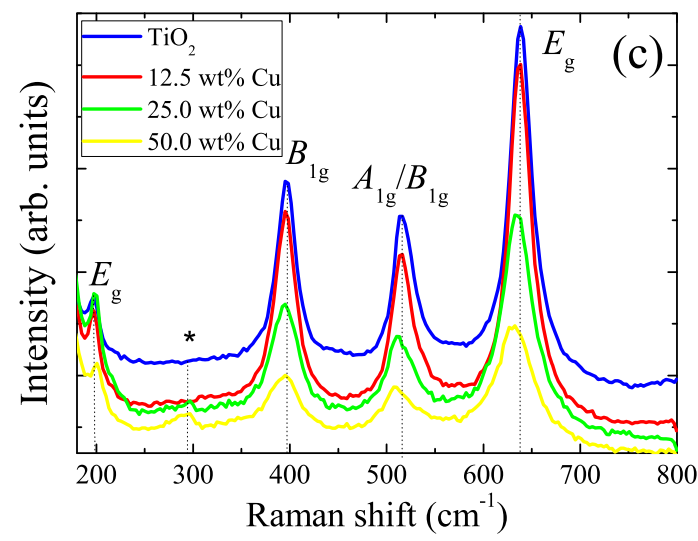

Fig. 2. (a) Raman spectra of pure and Copper-Titanium oxide thin films, (b) zoomed view of the $E_{\mathrm{g}}$ phonon mode at around $143 \mathrm{~cm}^{-1}$ in Raman spectra, (c) zoomed view of high frequency modes in Raman spectra. 

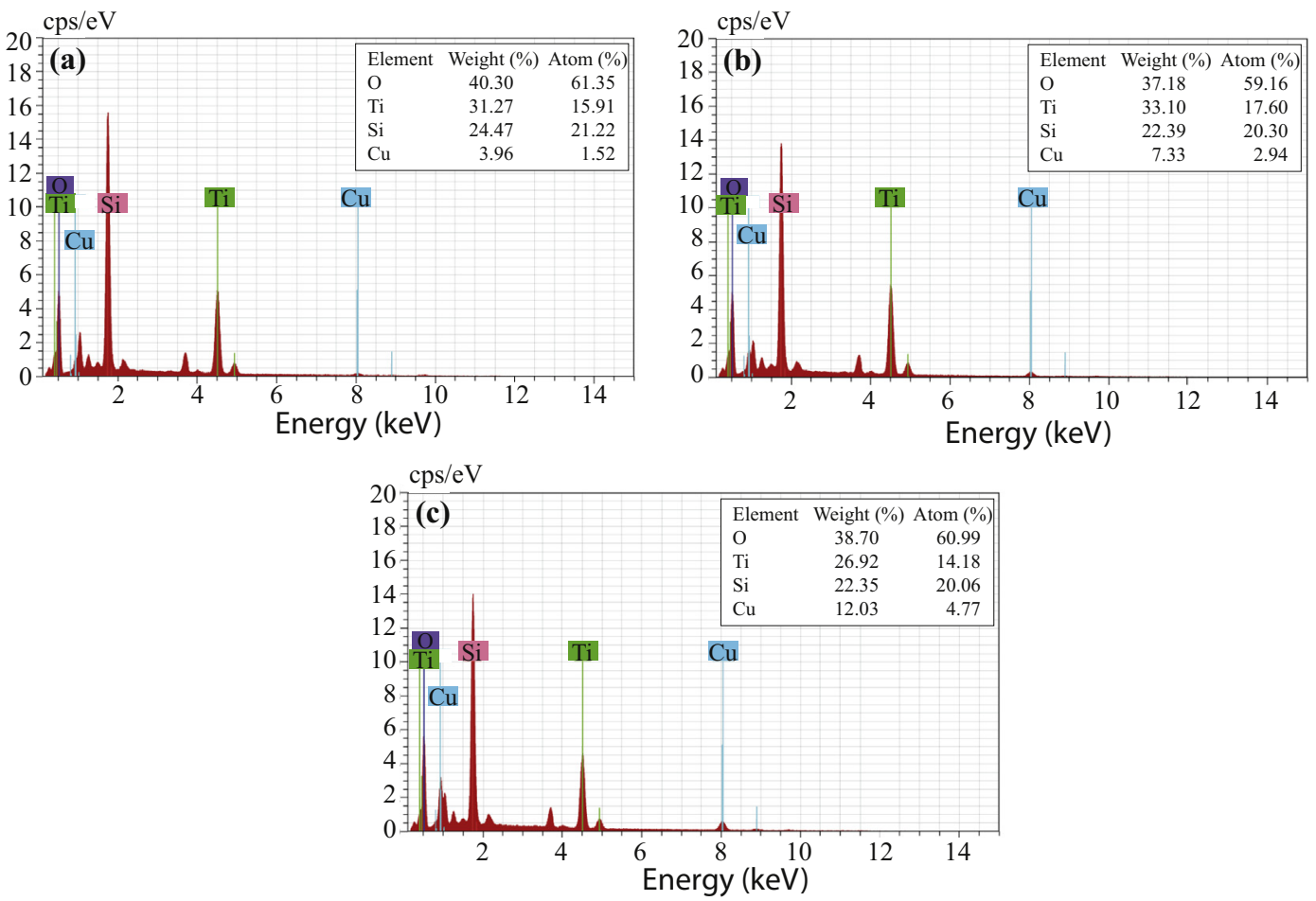

Fig. 3. EDX spectrums of (a) $12.5 \mathrm{wt} \% \mathrm{Cu}$ (b) $25.0 \mathrm{wt} \% \mathrm{Cu}$ and (c) $50.0 \mathrm{wt} \% \mathrm{Cu}$-incorporated films.

(a)

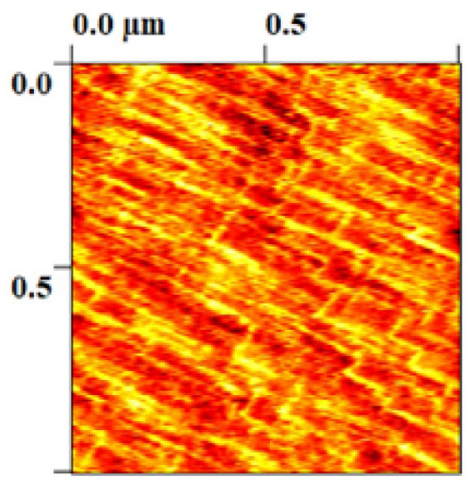

(b)
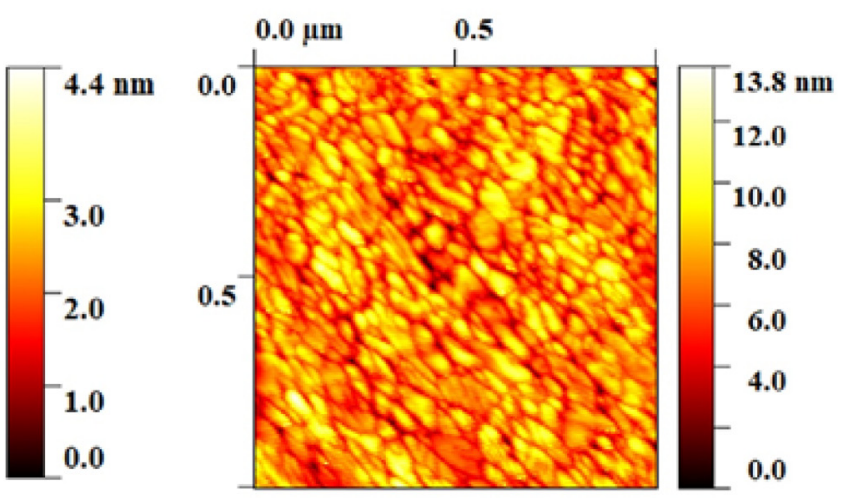

(c)
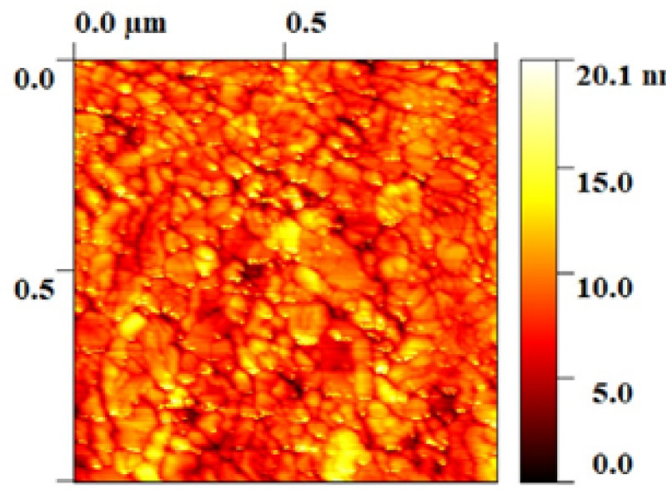

(d)

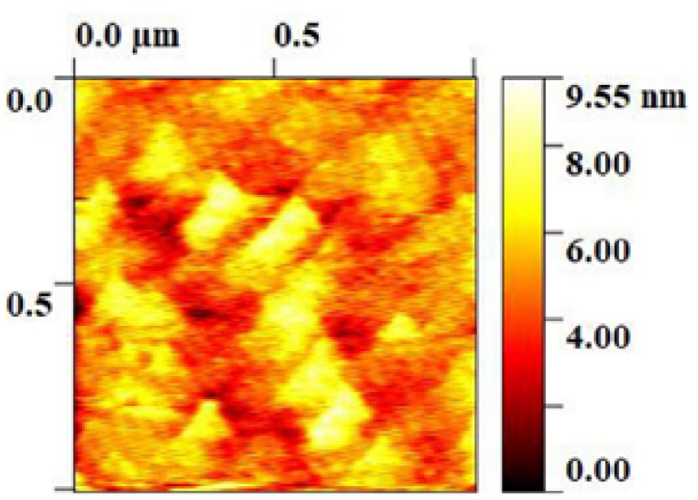

Fig. 4. $2 \mathrm{D}$ AFM images of (a) $\mathrm{TiO}_{2}$ (b) $12.5 \mathrm{wt} \% \mathrm{Cu}$ (c) $25.0 \mathrm{wt} \% \mathrm{Cu}$ and (d) $50.0 \mathrm{wt} \%$ Cu-incorporated films. 


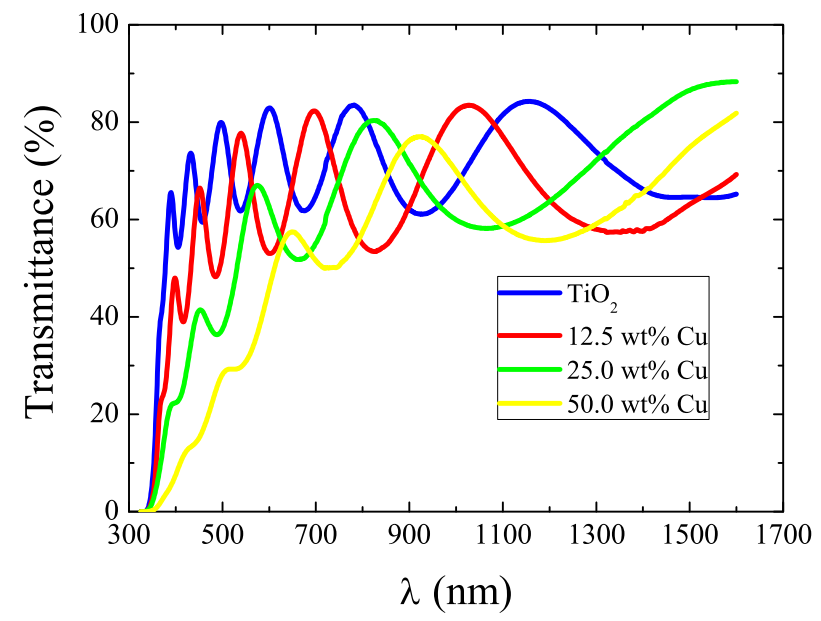

Fig. 5. The transmittance spectra of pure and Copper-Titanium oxide thin films.

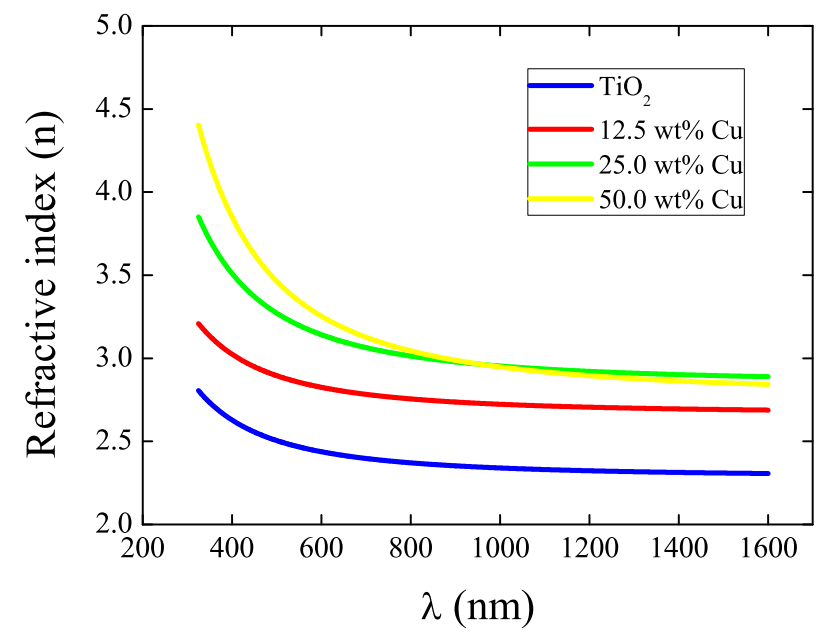

Fig. 6. Refractive index variation with wavelength of pure and CopperTitanium oxide thin films.

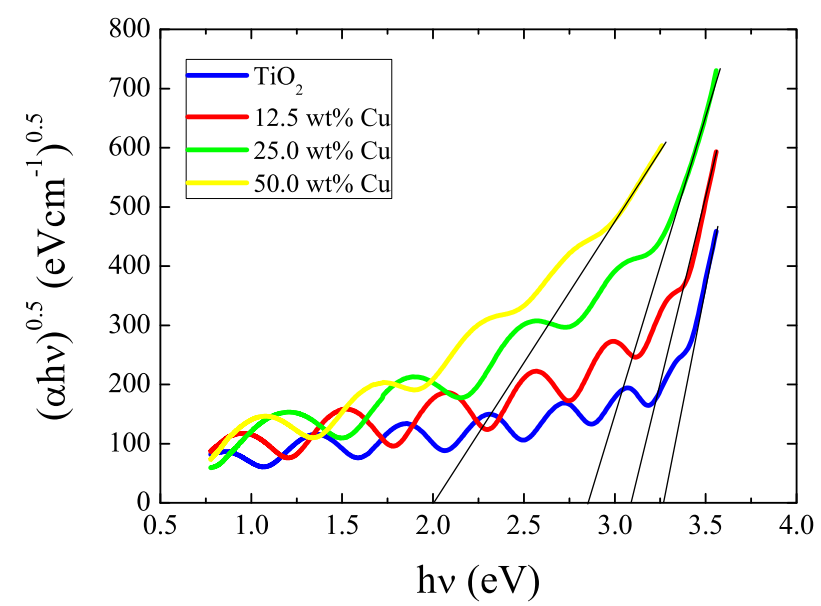

Fig. 7. Tauc plot of pure and Copper-Titanium oxide thin films.

where $n_{i}, \lambda_{i}, T_{M}$ and $T_{m}$ are the refractive index values and the wavelength at two adjacent extremes, the transmission maximum and the corresponding minimum of the spectra, respectively. The values of film thickness found by Eq. 2 are listed in Table 1. A significant decrease in film thickness is observed with the addition of copper. This is probably due to the increase in crystallinity and grain size of the film, as can be also seen from the XRD and AFM results [25,26].

In order to find the refractive index in the region of strong absorption where the interferences disappear; we can fit the experimental values of $\mathrm{n}$ to a reasonable function such as a two-term Cauchy dispersion relation $n=A+B / \lambda^{2}$. Fig. 6 shows the variation of $n$ with wavelength for Copper-Titanium oxide thin films. In this figure, the dispersion of $\mathrm{n}$ shows a decrease versus $\lambda$ and an increase in the magnitude of $\mathrm{n}$ as the doping increases. Such behavior is analogous to that reported for amorphous $\mathrm{TiO}_{2}$ films grown by different method [27] and polycrystalline $\mathrm{TiO}_{2}$ films grown by the same method [28]. The refractive index values of Copper-Titanium oxide thin films at $550 \mathrm{~nm}$ reference wavelength are given in Table 1 . The refractive index value of $\mathrm{TiO}_{2}$ obtained as 2.47 is consistent with other results in the literature [29]. In addition, it is seen that the refractive index at $550 \mathrm{~nm}$ increases as $\mathrm{Cu}$ content in the film increases.

$\alpha=\frac{1}{d} \ln \left(\frac{1}{T}\right)$ The optical band gap value, $E_{g}$, of the films are determined using the Tauc relation [30].

$\alpha h \nu=\alpha_{0}\left(h \nu-E_{g}\right)^{n}$

where $\mathrm{h} \nu$ is the photon energy, $\alpha_{\mathrm{o}}$ is a constant and $\mathrm{n}$ depends on electronic transitions in $\mathrm{k}$ space. Since $\mathrm{TiO}_{2}$ is an indirect semiconductor, the value of exponent is chosen as $n=2$. Fig. 7 shows ( $\alpha h v)$ ${ }^{1 / 2}$ vs. $h v$ plots of Copper-Titanium oxide thin films. The optical band gap values found by extrapolating the linear portion of the graphs to $\alpha=0$, on energy axis, are given in Table 1 . The optical band gap value of pure $\mathrm{TiO}_{2}$ is obtained as $3.26 \mathrm{eV}$ which is in agreement with the values reported previously $[14,31,32]$. After the high $\mathrm{Cu}$ addition, the absorption of visible light increases and the optical band gap decreases to $2.05 \mathrm{eV}$ for $50 \mathrm{wt} \% \mathrm{Cu}$-incorporated films. The decrease in $\mathrm{E}_{\mathrm{g}}$ value with increasing $\mathrm{Cu}$ content is due to the creation of impurity levels of Cu-3d states on the top of valence band in $\mathrm{TiO}_{2}[14,23]$.

\section{Conclusions}

In this study, the effect of high $\mathrm{Cu}$ incorporation on the optical and structural properties of $\mathrm{TiO}_{2}$ films is investigated. The presence of $\mathrm{Cu}$, $\mathrm{Ti}$ and $\mathrm{O}$ atoms in the films is seen in XRD patterns, Raman and EDX spectra. Since the ionic radius of the $\mathrm{Cu}$ atom is close to that of titanium atom, the $\mathrm{Cu}$ atoms are replaced by titanium atoms and titanium-copper compound forms. As a result, the optical band gap decreases from $3.26 \mathrm{eV}$ to $2.05 \mathrm{eV}$ and refractive index at $550 \mathrm{~nm}$ wavelength increases from 2.47 to 3.34 in pure and $50 \mathrm{wt} \% \mathrm{Cu}$-incorporated $\mathrm{TiO}_{2}$, respectively. Our results show that structural properties and optical characteristics such as refractive index and band gap values can be modified with heavily $\mathrm{Cu}$ incorporation.

\section{Acknowledgments}

This work was supported by TUBITAK-BIDEB 2218-National Postdoctoral Research Project. We would also like to thank Prof. Dr. Abdullah Yildiz for providing the XRD measurements.

\section{References}

[1] F. Bensouici, M. Bououdina, A. A. Dakhel, R. Tala-Ighil, M. Tounane, A. Iratni, T. Sourier, S. Liu, W. Cai, Optical, structural and photocatalysis properties of Cudoped $\mathrm{TiO}_{2}$ thin films, Appl. Surf. Sci. 395 (2017) 110-116.

[2] R.S. Dubey, V. Ganesan, Reflectance modulation using $\mathrm{SiO}_{2} / \mathrm{TiO}_{2}$ multilayer structures prepared by sol-gel spin coating process for optical applications, Superlattices and Microstruc. 111 (2017) 1099-1103.

[3] W.-R. Kim, H. Park, W.-Y. Choi, $\mathrm{TiO}_{2}$ micro-flowers composed of nanotubes and their application to dye-sensitized solar cells, Nanoscale Res. Lett. 9 (2014) 1-10.

[4] P.M. Faia, C.S. Furtado, A.J. Ferreira, AC impedance spectroscopy: a new equivalent circuit for titania thick film humidity sensors, Sens. and Act. B 107 (2005) 353-359.

[5] Y. Li, W. Wlodarski, K. Galatsis, S.H. Moslih, J. Cole, S. Russo, N. Rockelmann, Gas sensing properties of p-type semiconducting $\mathrm{Cr}$-doped $\mathrm{TiO}_{2}$ thin films, Sens. and Act. B 83 (2002) 160-163.

[6] L. Sang, J.L. Gole, J. Wang, J. Brauer, B. Mao, S.M. Prokes, C. Burda, Phase transformation and charge transfer in heavily Iron ion doped titanium oxide and 
Oxynitride Nanocolloids, J. Phys. Chem. C 117 (2013) 15287-15294.

[7] L. Gomathi Devi, S. Girish Kumar, Influence of physicochemical-electronic properties of transition metal ion doped polycrystalline titania on the photocatalytic degradation of Indigo Carmine and 4-nitrophenol under UV/solar light, Appl. Surf. Sci. 257 (2011) 2779-2790.

[8] M.-C. Wu, P.-Y. Wu, T.-H. Lin, Tz-F. Lin, Photocatalytic performance of Cu-doped $\mathrm{TiO}_{2}$ nanofibers treated by the hydrothermal synthesis and air-thermal treatment, Appl. Surf. Sci. 430 (2018) 390-398.

[9] H. Liu, L. Gao, Preparation and properties of Nanocrystalline $\alpha-\mathrm{Fe}_{2} \mathrm{O}_{3}$-sensitized $\mathrm{TiO}_{2}$ Nanosheets as a visible light Photocatalyst, J. Am. Ceram. Soc. 89 (2006) 370-373.

[10] H. Zhang, X. Yu, J.A. McLeod, X. Sun, First-principles study of cu-doping and oxygen vacancy effects on $\mathrm{TiO}_{2}$ for water splitting, Chem. Phys. Lett. 612 (2014) $106-110$.

[11] M. Maeda, T. Yamada, Photocatalytic activity of metal-doped titanium oxide films prepared by sol-gel process, J. Phys. Conf. Ser. 61 (2007) 755.

[12] C. Wang, Q. Hu, J. Huang, C. Zhu, Z. Deng, H. Shi, L. Wu, Z. Liu, Y. Cao, Enhanced hydrogen production by water splitting using cu-doped $\mathrm{TiO}_{2}$ film with preferred (001) orientation, Appl. Surf. Sci. 292 (2014) 161-164.

[13] M.I. Khan, M. Mujeeb, U. Faroog, Sol-gel deposition and electrical properties of laser irradiated $\mathrm{Cu}$ doped $\mathrm{TiO}_{2}$ multilayer thin films, Results in Physics 7 (2017) 2485-2488.

[14] H. Wang, Y. Li, X. Ba, L. Huang, Y. Yu, $\mathrm{TiO}_{2}$ thin films with rutile phase prepared by DC magnetron co-sputtering at room temperature: effect of $\mathrm{Cu}$ incorporation, Appl. Surf. Sci. 345 (2015) 49-56.

[15] J. Yu, X. Zhao, Q. Zhao, Effect of film thickness on the grain size and photocatalytic activity of the sol-gel derived nanometer $\mathrm{TiO}_{2}$ thin films, J. Mater. Sci. Lett. 19 (2000) 1015-1017.

[16] S. Sharma, S. Chaudhary, S.C. Kashyap, S.K. Sharma, Room temperature ferromagnetism in $\mathrm{Mn}$ doped $\mathrm{TiO}_{2}$ thin films: electronic structure and Raman investigations, J. Appl. Phys. 109 (2011) 083905.

[17] T. Ohsaka, S. Yamaoka, O. Shimomura, Effect of hydrostatic pressure on the Raman spectrum of anatase $\left(\mathrm{TiO}_{2}\right)$, Solid State Commun. 30 (1979) 345-347.

[18] G.R. Hearne, J. Zhao, A.M. Dawe, V. Pischedda, M. Maaza, M.K. Nieuwoudt, P. Kibasomba, O. Nemraoui, J.D. Comins, M.J. Witcomb, Effect of grain size on structural transitions in anatase $\mathrm{TiO}_{2}$ : a Raman spectroscopy study at high pressure, Phys. Rev. B 70 (2004) 134102.

[19] F. Tian, Y. Zhang, J. Zhang, C. Pan, Raman spectroscopy: a new approach to measure the percentage of Anatase $\mathrm{TiO}_{2}$ exposed (001) facets, J. Phys. Chem. C 116 (2012) 7515-7519.

[20] M. Sahu, P. Biswas, Single-step processing of copper-doped titania nanomaterials in a flame aerosol reactor, Nanoscale Res. Lett. 6 (2011) 441-455.

[21] B. Choudhury, M. Dey, A. Choudhury, Defect generation, $d$-d transition, and band gap reduction in $\mathrm{Cu}$-doped $\mathrm{TiO}_{2}$ nanoparticles, International Nano Letters 3 (2013) 25.

[22] H. Hagemann, H. Bill, W. Sadowski, E. Walker, M. Francois, Raman spectra of single crystal CuO, Solid State Commun. 73 (1990) 447-451.

[23] V. Krishnakumar, S. Boobas, J. Jayaprakash, M. Rajaboopathi, B. Han, M. LouhiKultanen, Effect of $\mathrm{Cu}$ doping on $\mathrm{TiO}_{2}$ nanoparticles and its photocatalytic activity under visible light, J. Mater. Sci. Mater. Electron. 27 (2016) 7438-7447.

[24] R. Swanepoel, Determination of the thickness and optical constants of amorphous silicon, J. Phys. E: Sci. Instrum. 16 (1983) 1214-1222.

[25] U. Joost, R. Pärna, M. Lembinen, K. Utt, I. Kink, M. Visnapuu, V. Kisand, Heat treatment and substrate dependant properties of titania thin films with high copper loading, Phys. Status Solidi A 210 (2013) 1201-1212.

[26] V. Romanyuk, N. Dmitruk, V. Karpyna, G. Lashkarev, V. Popovych, M. Dranchuk, R. Pietruszka, M. Godlewski, G. Dovbeshko, I. Timofeeva, O. Kondratenko, M. Taborska, A. Ievtushenko, Optical and electrical properties of highly doped $\mathrm{ZnO}$ :Al films deposited by atomic layer deposition on Si substrates in visible and near infrared region, Acta Phys. Pol. A 129 (2016) A36-A40.

[27] M.L. Grilli, M. Yilmaz, S. Aydogan, B. Bozkurt Cirak, Room temperature deposition of XRD-amorphous $\mathrm{TiO}_{2}$ thin films: investigation of device performance as a function of temperature, Ceram. Int. 44 (2018) 11582-11590.

[28] E. Haimi, H. Lipsonen, J. Larismaa, M. Kapulainen, J. Krzak-Ros, S.-P. Hannula, Optical and structural properties of nanocrystalline anatase $\left(\mathrm{TiO}_{2}\right)$ thin films prepared by non-aqueous sol-gel dip-coating, Thin Solid Films 519 (2011) 5882-5886.

[29] Z. Wang, U. Helmersson, P.-O. Käll, Optical properties of anatase $\mathrm{TiO}_{2}$ thin films prepared by aqueous sol-gel process at low temperature, Thin Solid Films 405 (2002) 50-54.

[30] J. Tauc, Absorption edge and internal electric fields in amorphous semiconductors, Mater. Res. Bull. 5 (1970) 721-729.

[31] B. Houng, C.C. Liu, M.T. Hung, Structural, electrical and optical properties of molybdenum-doped $\mathrm{TiO}_{2}$ thin films, Ceram. Int. 39 (2013) 3669-3676.

[32] R. López, R. Gómez, M.E. Lianos, Photophysical and photocatalytic properties of nanosized copper-doped titania sol-gel catalysts, Catal. Today 148 (2009) 103-108. 